\title{
Clinical Experience with Expanded Polytetrafluoroethylene Sheet Used as an Artificial Dura Mater
}

\author{
Sen Yamagata, Kazuo Goto, Yoshifumi OdA and Haruhiko KIKUCHI \\ Department of Neurosurgery, Kyoto University School of Medicine, Kyoto
}

\begin{abstract}
Dural repair using chemically treated cadaveric dura mater often results in atrophic and fragile change of the substitute as well as adhesion between the dura mater and brain surface at reoperation. Creutzfeldt-Jakob disease has occurred after repair using cadaveric dura mater. Expanded polytetrafluoroethylene (EPTFE) surgical sheet was used for dural repair in 34 patients. Suturing of EPTFE was easy and the incidence of cerebrospinal fluid accumulation in the epidural space was the same as when cadaveric dura mater was used. Six patients underwent reoperation, 1-15 months after the first operation. At reoperation the EPTFE sheet showed no change except for becoming transparent, and the strength was well preserved. A very thin layer of granulation tissue was formed between the EPTFE sheet and brain surface, but the EPTFE sheet was easily detached from the brain surface without adhesion even 15 months after the first operation. Our results suggest that the EPTFE sheet can be used safely and effectively as an artificial dura mater.
\end{abstract}

Key words: expanded polytetrafluoroethylene,

dura mater, artificial organ

\section{Introduction}

Defects of the dura mater caused by craniotomy are conventionally repaired using substitute dura mater (Lyodura ${ }^{(i)}$ ) manufactured by chemically processing dura mater from cadavers. However, reoperation in patients several months after dural graft replacement has sometimes shown degenerative atrophy and insufficient strength of the cadaveric dura mater. The graft may also adhere to the underlying brain tissue. Creutzfeldt-Jakob disease may develop after the use of cadaveric dura mater..$^{6,12,13)}$

Here we report our tests of a new artificial dura mater made of expanded polytetrafluoroethylene (EPTFE) sheet (Gore-Tex ${ }^{\circledast}$ ), which was anticipated to develop no reaction to the living body and no adhesion to the surrounding tissue.

\section{Clinical Materials and Methods}

This study included 34 patients, 22 with brain or spinal tumor, six with arteriovenous malformation, three with head trauma, two with intracranial hematoma, and one with ruptured intracranial aneurysm, who all underwent repair of the dura mater using white, $0.1 \mathrm{~mm}$-thick EPTFE sheet cut to a size slightly greater than the defect, and fixed by continuous suture to the surrounding dura mater. Six of these 34 patients underwent craniotomy again for various reasons, $1-15$ months after the initial operation.

We examined the use of this sheet in defect repair, and the incidence of postoperative cerebrospinal fluid (CSF) accumulation and infection. Adhesion of the sheet to the brain tissue and the strength were investigated at re-craniotomy. 


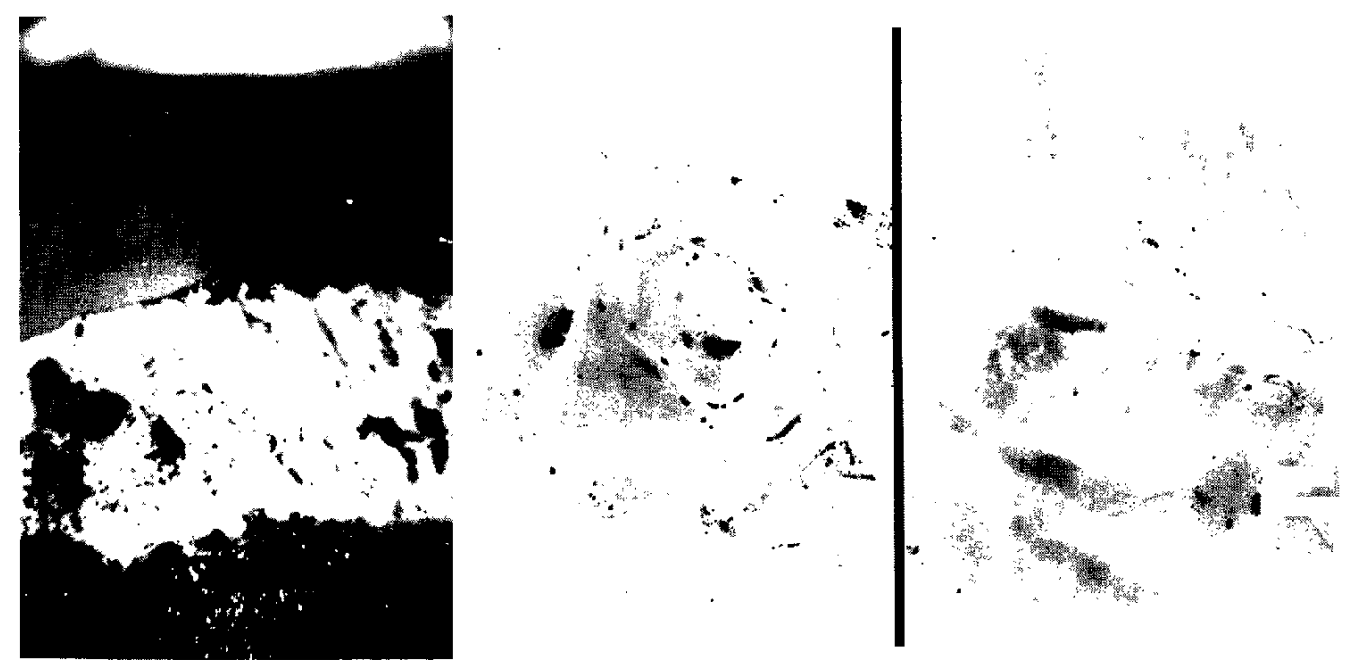

Fig. 1 Photographs taken during reoperation. left: One month after dural repair, the white EPTFE sheet has become partially semi-transparent. center: Four months later, the EPTFE sheet has become entirely semi-transparent. When the semi-transparent sheet was incised and inverted, little adhesion to the brain tissue was observed. right: Fifteen months later, the strength of the sheet was well preserved, and no adhesion to the brain surface was found.

\section{Results}

Suturing of the EPTFE sheet to the surrounding intact dura mater was quite satisfactory, and no problem was found with the sutures. The needle passed smoothly through the sheet without any breaks. However, immediately after suturing, the adaptability of the EPTFE sheet to the intact dura mater was slightly poor, because the elasticity of the EPTFE sheet is slightly lower than cadaveric dura mater. The EPTFE sheet was very white, so it strongly reflected light from the astral lamp, sometimes dazzling the surgeons.

Mild postoperative CSF accumulation occurred in five patients, a similar incidence to that with the cadaveric dura mater. No postoperative meningitis, CSF rhinorrhea, or adverse reactions such as abscess formation were observed.

Reoperation revealed that the sheet had a macular appearance of white and semi-transparent regions about 1 month after the initial operation (Fig. 1 left). About 4 months after the operation, the sheet was semi-transparent over the entire surface (Fig. 1 center), causing the impression that the EPTFE sheet had disappeared. No adhesion of the sheet to the scalp or subcutaneous tissue occurred. No adhesion of the sheet to the brain tissue was found even 15 months after the initial operation, and the sheet could be easily detached from the brain surface without injuring the brain (Fig. 1 right). A thin,

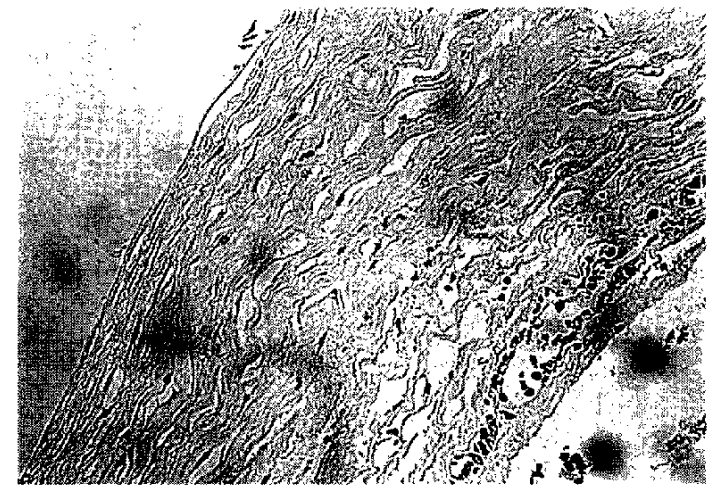

Fig. 2 Histological examination of the membrane-like tissue formed between the sheet and the brain tissue obtained during reoperation 4 months after repair. Note the mild cellular infiltration and granulation. HE stain, $\times 100$.

transparent membrane-like tissue was found between the sheet and the brain surface. This membrane was confirmed histologically to be granulation tissue (Fig. 2). The strength of the sheet was preserved well even 15 months after the initial operation and did not require renewal.

\section{Discussion}

Polytetrafluoroethylene is formed of tetrafluoro- 
ethylene monomers. The molecular weight ranges from 400,000 to $10,000,000$. The fluorine atoms surround the carbon skeleton like a sheath, achieving great stability against various chemical reactions. A porous material made of EPTFE has been used for artificial vessels ${ }^{7)}$ and patches for pericardium clinically. ${ }^{8,(0)}$ The results to date indicate that EPTFE has long-term durability in vivo, with little reaction or adhesion to living tissue. These features make EPTFE suitable as an artificial dura mater.

The present study using EPTFE sheets and our past experience with cadaveric dura mater show that the simplicity of suturing to intact dura mater and the incidence of CSF collection or leakage after surgery were the same with both materials. Reoperation showed that the EPTFE sheet did not adhere to the scalp, subcutaneous tissue, or brain tissue. Although a very thin connective tissue was formed between the EPTFE sheet and the brain surface below, the EPTFE sheet was easy to detach from this connective tissue. For these reasons, reoperation after dural repair with EPTFE sheet caused no injury to the brain surface. Also, the sheet strength was well preserved even 15 months after initial operation.

A minor improvement for EPTFE sheet is a change of color to prevent bright reflection of light from an astral lamp. A transparent sheet would be advantageous during dural suturing so that conditions below the dura mater such as bleeding could be checked easily.

The use of cadaveric dura mater may result in the onset of Creutzfeldt-Jakob disease. ${ }^{6,12-14)}$ The pathogen responsible for this disease is resistant to $10 \%$ formaldehyde, $70 \%$ alcohol, boiling, ultraviolet radiation, and ionizing radiation. ${ }^{2,4}$ Therefore, the pathogen may not be inactivated by the current sterilization procedure used for commercially prepared cadaveric dura mater graft. Creutzfeldt-Jakob disease of an iatrogenic origin") includes cases caused by corneal implantation, administration of a growth hormone derived from cadaver pituitary glands, ${ }^{\text {s }}$ and insertion of an electrode into the skull, as well as neurosurgical procedures such as operation for trigeminal neuralgia") or brain tumor removal. ${ }^{3,111}$ Equipment used for surgery is sterilized by methods inactivating the pathogen, such as high-pressure sterilization at $132^{\circ} \mathrm{C}$, so it is unlikely that the Creutzfeldt-Jakob pathogen is transmitted via the surgical tools. We cannot eliminate the transmission of the pathogen via the cadaveric dural graft. Moreover, an unknown pathogen may cause serious disease in the future if cadaveric organ grafts are employed. Therefore, we should avoid the use of cadaveric organs, and employ artificial substitutes if possible.

\section{References}

1) Bernoulli C, Siegfried J, Baumgartner G, Regli F, Rabinowicz T, Gajdusek DC, Gibbs CJ Jr: Danger of accident person-person transmission of Creutzfeldt-Jakob disease by surgery. Lancet 1: 478-479, 1977

2) Brown P, Gibbs CJ Jr, Amyx HL, Kingsbury DT, Rohwwer RG, Sulima MP, Gajdusek DC: Chemical disinfection of Creutzfeldt-Jakob disease virus. $N$ Engl J Med 306: 1279-1282, 1982

3) Gaches J, Supono-Vitebo V, Oughourlian JM: Unusual electroencephalographic and clinical evolution of a case of meningioma of the left temporo-occipital convexity. Eur Neurol 5: 155-164, 1971

4) Gajdusek DC, Gibbs CJ Jr, Asher DM, Brown P, Diwan A, Hoffman P, Nemo G, Rohwer R: Precautions in medical care of, and in handling materials from, patients with transmissible virus dementia (Creutzfeldt-Jakob disease). $N$ Engl $J$ Med 297: 1253-1258, 1977

5) Koch TK, Berg BO, De Armond SJ, Gravina RF: Creutzfeldt-Jakob disease in a young adult with idiopathic hypopituitarism. Possible relation to the administration of cadaveric human growth hormone. $N$ Engl J Med 313: 731-733, 1985

6) Masullo C, Pocchiari M, Macchi G, Alema G, Piazza G, Panzera MA: Transmission of Creutzfeldt-Jakob disease by dural cadaveric graft. $J$ Neurosurg 71 : 954 , 1989

7) Matsumoto H, Fuse K, Fukushima K, Yamamoto M, Hasegawa T, Saigusa M, Hasegawa Y: Experimental studies on the expanded polytetrafluoroethylene as the vascular prosthesis: The second report: Its application to vein. Jinko Zoki 2: 262-267, 1973 (in Japanese)

8) Matsumoto $\mathbf{H}$, Matsunaga $\mathbf{H}$, Saigusa $\mathbf{M}$ : Usefulness of multi-axially expanded polytetrafluoroethylene in cardiac surgery: Patches applicable to atrial septum. Kyobu Geka 29: 1130-1134, 1981 (in Japanese)

9) Matthews WB: Epidemiology of Creutzfeldt-Jakob disease in England and Wales. I Neurol Nearosurg Psychiatry 38: 210-213, 1975

10) Minale $C$, Nikol S, Hollweg G, Mittermayer $C$, Messmer BJ: Clinical experience with expanded polytetrafluoroethylene Gore-Tex surgical membrane for pericardial closure: A study of 110 cases. I Card Surg 3: 193-201, 1988

11) Nevin S, McMenemey WH, Behrman S, Jones DP: Subacute spongiform encephalopathy: A subacute form of encephalopathy attributable to vascular dysfunction (spongiform cerebral atrophy). Brain 83: 519-564, 1960

12) Nisbet TJ, MacDonaldson I, Bishara SN: Creutzfeldt-Jakob disease in a second patient who received a cadaveric dura mater graft. JAMA 261: 1118, 1989

13) Prichard J, Thadani V, Kalb R, Manuelidis E: Rap- 
idly progressive dementia in a patient who received a cadaveric dura mater graft. $M M W R$ 36: 49-50, 1987

14) Thadani V, Penar PL, Partington J, Kalb R, Janssen $R$, Schonberger LB, Rabkin CS, Prichard JW: Creutzfeldt-Jakob disease probably acquired from a cadaveric dura mater graft. Case report. $J$ Neurosurg 69: $766-769,1988$
Address reprint requests to: S. Yamagata, M.D., Department of Neurosurgery, Shiga Medical Center for Adult Diseases, 328-1 Moriyama-cho, Moriyama, Shiga 524, Japan. 